\title{
Dragonflies Diversity (Odonata) in Menoreh Karst Central Java - Yogyakarta
}

\author{
Hening Triandika Rachman ${ }^{1}$, and Abdu Rohman ${ }^{2}$
}

\begin{abstract}
This study aims to determine the diversity of dragonfly species and diversity index of dragonfly species due to tourism in the Menoreh Karst Central Java - Yogyakarta. Data were collected at three different locations in Kulonprogro tourism area ( Kedung Pedut Waterfall, Banyu Mudal Waterfall and Anjani Waterfall ). Location for data collection based on the availability of water resources using purposive sampling method. The species were identified using identification books (Dragonfly of Singapore and Australian Dragonfly). The diversity index is analyzed using Shannon -Weinner diversity index. Based on research we revealed 11 species of dragonflies are exist in three sampling locations (Leptogomphus lansbergei, Orthethrum sabina, Pantala flavecens, Diplacodes trivialis and Potamarcha congeners, Euphaea variegata, Nososticta insignis, Drepanosticta sundana, Drepanosticta gazella, Vestalis luctosa and Coellicia membranipes). 7 species are vulnerable to water pollution. 3 species are endemic to Javan Island.
\end{abstract}

Keywords- Biodiversity, Odonata, Diversity Index, Menoreh, Central Java Yogyakarta.

\section{INTRODUCTION}

Menoreh Karst are formed in Jonggrangan Formation which lies on the border between the Kulon Progo District and Purworejo District. Menoreh Karst areal estimated more than $15 \mathrm{~km}^{2}$ stretching from north to south. Northern and southern part have hill contour, while the central part is relatively flat. The east and west are bordered by a cliff, one of the cliff called Tebing Kelir that reach tens to hundreds of meters. Menoreh Karst have lowland tropical rain forest habitat type. Menoreh Karst have potency for tourism including caves and waterfalls [9]. Tourism locations in Menoreh Karst that attract alot of tourist are Kedung Pedut Waterfall, Banyu Mudal Waterfall and Anjani Waterfall. The potency of waterfall tourism does not balanced by a conservative action, thereby potentially causing environmental damage and destabilize the biota. Dragonfly is one of the organisms that live in the waterfall flow in Menoreh Karst. The life cycle of the dragonfly is depend on the availability and quality of water, some species of dragonfly are vulnerable to water pollution such as habitat change, pollution and disturbance from human activities [5]. Based on research from 2010 - 2016 [7] and research in 2015 [3] there are 16 species of dragonflies in Menoreh Karst region. 2 dragonfly species are endemic to Java

\footnotetext{
${ }^{1}$ Departement of Biology Education, Faculty of Mathematics and Science, Yogyakarta State University

${ }^{2}$ Departement of Biology, Faculty of Biology, Gadjah Mada University
}

Island (Nososticta insignis, Drepanosticta sundana, Drepanosticta gazella). Some of dragonfly nymph are very sensitif to water pollutions because their whole life are spend in the water . Conservative action that can be done to prevent dragonfly extinction is by inventary the dragonfly diversity that live in Menoreh Karst areal, especially in waterfall. Based on the problem we are interest to study about dragonfly diversity in Menoreh Karst areal. The research result hopefully able to determine the impact of tourism to dragonfly diversity, then it can be used to reference in how to manage waterfall for tourism and also long-term conservation.

\section{RESEARCH METHOD}

\section{A. Observation}

Determining the location for data collection started by observe in menoreh karst waterfall. The chosen location is waterfalls that used in tourism (Ajani Waterfalls, Banyu Mudal Waterfall and Kedung Pedut Waterfalls).

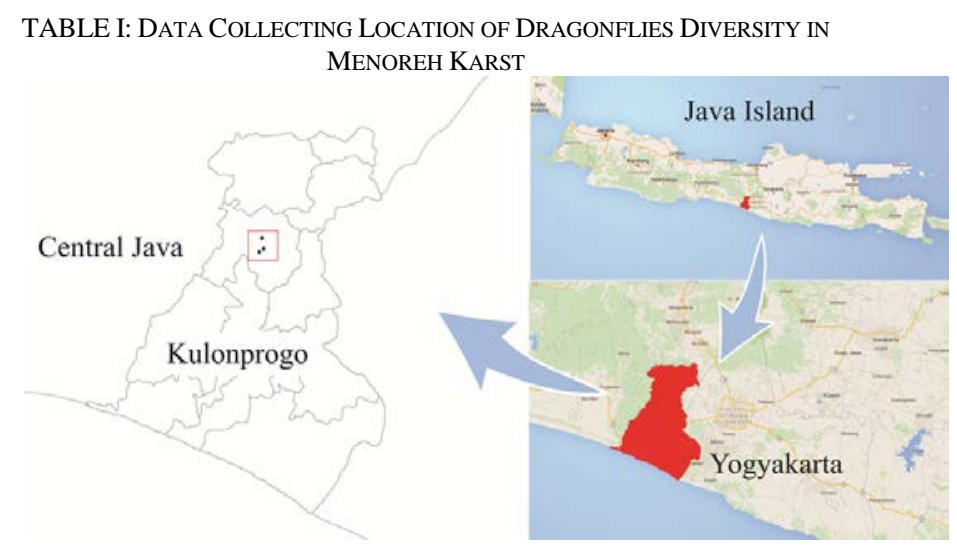

\section{B. Data Collection}

Data collection is using purposive sampling method. This method performed during the dragonfly active (08:00-15:00) West Indonesian Time. Data collection was repeated three times for each waterfall. Other observations outside the sampling time is taken to strengthen data and also for documentation.

\section{C.Dragonflies Counting}

Counting the number of each dragonfly species is done directly in their habitat. Calculations performed three times for each location. The data then averaged for each location. 


\section{D.Recording Morphological Characteristic}

Recording morphological characteristics performed on dragonfly that found. Dragonfly catched by insect net then record their morphological caharactersitic. Minimum recording is 3 individuals at least for each species. Recording morphological characteristics is used to check whether the species is recorded previously or not. Each species is documentated for easier identification.

\section{E. Data Analysis}

Data species from morphological characteristics recording and documentation identified using the identification book (Dragonfly of Singapore and Australian Dragonfly).

Number of individuals that obtained analyzed using Shannon-Wiener diversity index. According to the ShannonWiener, the criteria of species diversity indicates, if $\mathrm{H}>3$ means the species diversity is high. If the value $H ' 1 \leqslant H \leqslant 3$ means the level of diversity is medium, whereas if $\mathrm{H}^{\prime}<1$ means the level of diversity is low.

Shannon-Weinner Diversity Index calculated according to Odum (1998):

$$
H^{\prime}=-\underline{n i} \Sigma \log \frac{n i}{N}
$$

Information:

H' = Shannon-Weinner diversity index

$\mathrm{Ni}=$ Number of individual in some i species

$\mathrm{N}=$ Total number of individual in all species

\section{RESULT AND DISCUSSION}

The results of research at three locations (Kedung Pedut Waterfall, Banyu Mudal Waterfall and Anjani Waterfall) found there are 11 species of dragonflies exist. Anisoptera suborder consists of five species (Leptogomphus lansbergei, Orthethrum sabina, Pantala flavecens, Diplacodes trivialis and Potamarcha congeners). Zygoptera suborder consists of six species (Euphaea variegata, Nososticta insignis, Drepanosticta sundana, Drepanosticta gazella, Vestalis luctosa and Coellicia membranipes ).

Selection of the 3 research sites based on the presence of water and the utilization of water resources as a tourism. The first location is Anjani Waterfall. There are 11 species found in Anjani Waterfall. Anjani Waterfall has 7 meter high, the flow of water coming from the hills springs that not many human activities there. Around the waterfall is covered by secondary forests that are still good and not suffered alot of damage. Anjani Waterfall is a sample location that least human disturbance and there is no water pollution from human Anjani Waterfall is sample location that we found the most of dragonflies. Water pollution occurs below arround 15 meters from waterfall. Water stream is used for pool, so that the water that coming out from the swimming pool is mixed with a lot of contaminants. All vulnerable species to water pollution and human disturbance still can be found arround waterfall
(Nososticta insignis, Vestalis luctosa, Coellicia membranipes, Drepanostica Sundana, Drepanostica gazella, Leptogomphus lansbergei and Euphaea variegata).

The second location is the Banyu Mudal Waterfall. There are 9 species were found in Banyu Mudal Waterfall. The flow of water coming from the fountain hills. The springs that coming out used to tourism area. Right beside the fountain there is a playground and lodging. Banyu Mudal Waterfall is the longest waterfall compared to other location. Banyu Mudal Waterfall have length arround 30 meters. Less dragonfly species were found. Dragonfly species that are vulnerable to water pollution only found 4 species (Nososticta insignis, Vestalis luctosa, Coellicia membranipes and Euphaea variegata).

The last area is Kedung Pedut Waterfall. There are only 6 species found in Kedung Pedut Waterfall. The flow of water comes from Banyu Mudal Waterfall. It means that already contaminated from previous flow. Kedung Pedut Waterfall is the most visited by tourists than the other two locations. The water flow also dammed and manipulated for tourism. Around this area a lot of semi-permanent building and delicatessen. Forests around the waterfalls is cutten down. Number of dragonflies found in Waterfall Kedung is the most few. Species that are vulnerable to water pollution only found 1 species (Nososticta insignis).

Dragonfly that classified as vulnerable species to water pollution in the all sampling locations are seven species (Euphaea variegata, Nososticta insignis, Drepanosticta sundana, Drepanosticta gazella, Vestalis luctosa, Coellicia membranipes, Leptogomphus lansbergei ). 3 dragonfly are Javan endemic species ( Nososticta insignis, Drepanosticta sundana and Drepanosticta gazella). The discovery of the seven species is an indication of the quality of the waterfall flow remains good. However, the data shows that human disturbance causing dragronfly diversity decrease.

Two new species were recorded in this research (Leptogomphus lansbergei and Drepanosticta gazella). Leptogomphus lansbergei is one of Gomphidae Family. Gomphidae is dragonfly with separated eyes and medium size. Leptogomphus lansbergei is very rare in Javan Island. Drepanosticta gazella is Platysticdae Family. Drepanosticta gazella have bluish line in the thorax side so it makes easily to identify. Drepanosticta gazella size is very small. This new recorded species were not found in research before [3]. Pungki Lupiyaningdyah research conducted in 4 different locations (Kaligesing, setawung waterfall, river katerban and seplawan). Two new species can be found only arround Anjani Waterfall. The discovery of two new dragonfly species indicates that diversity increasing in Menoreh Karst still possible, so that further exploratory research should be done. The photos of new recorded species are shown in table. 3 below. 
TABLE II: NEW RECORDED DRAGONFLy PHOTO

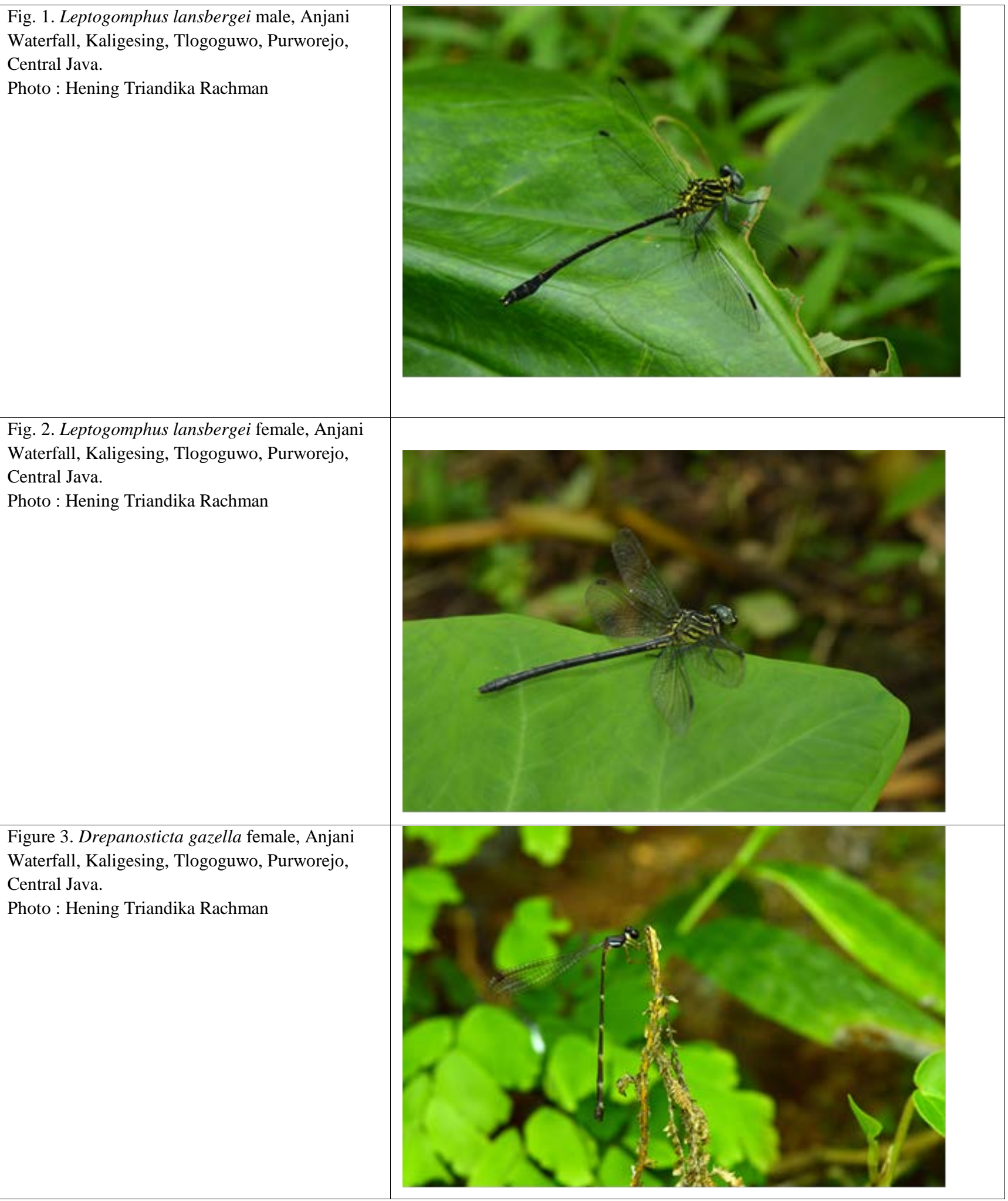

The results of dragonfly diversity analysis using the Shannon-Weinner diversity index shows Leptogomphus lansbergei has 0,040 diversity index. Orthethrum sabina has 0.147 diversity index. Pantala flavecens has 0.134 diversity index. Diplacodes trivialis has 0.077 diversity index.
Potamarcha congener has 0.104 diversity index. Euphaea variegata has 0.100 diversity index. Nososticta insignis has 0.100 diversity index. Drepanosticta Sundana has 0.040 diversity index. Drepanosticta gazella has 0.048 diversity index. Vestalis luctosa 0.071 diversity index. Coellicia membranipes has 0.077 diversity index. The higher diversity 
index is Orthethrum sabina. The smallest diversity index Drepanosticta sundana. Dragonfly diversity index chart can be seen in the diagram Table.III Dragonfly diversity index of Menoreh Karst is under 1, so it can be concluded that the diversity of dragonflies in the third sampling locations is low. This low dragonfly diversity index in Menoreh Karst should be concern for researchers, government and tourism management. The presence of 7 vulnerable species that are vulnerable to water pollution and also the presence of three Javan endemic species that lives in Menoreh Karst we should be keep them from existance. If the goverment continue opening new tourism area in Menoreh Karst and doesnt accompanied by conservation, spesies extinction it is possible.

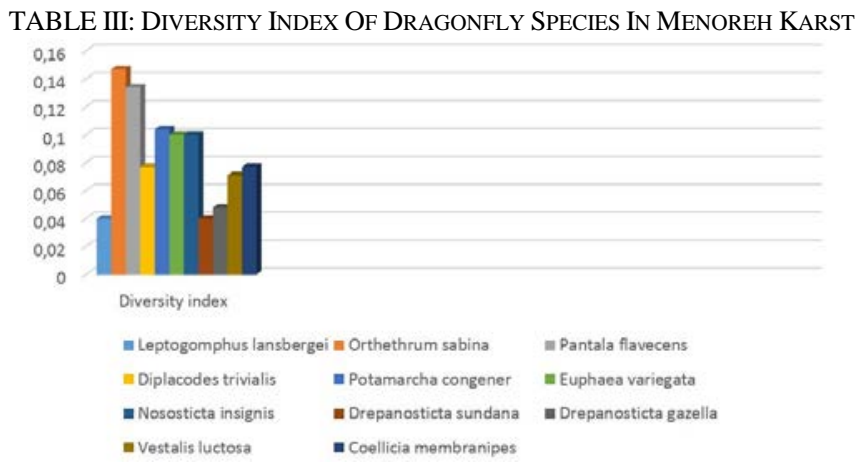

\section{CONCLUSION}

This research shows there are 11 species of dragonflies (Leptogomphus lansbergei, Orthethrum sabina, Pantala flavecens, Diplacodes trivialis, Potamarcha congeners, Euphaea variegata, Nososticta insignis, Drepanosticta Sundana, Drepanosticta gazella, Vestalis luctosa and Coellicia membranipes) that live in 3 waterfall Menoreh Karst.

Utilization of Waterfall in Menoreh Karst to become tourism area causes loss of dragonflies species diversity. Tourism causing several problem such as: habitat changing, disappearing of vegetation, environmental pollution and disturbance by human activity. These factors led dragonfly move away from the habitat, nymph death, lack of food sources, and dragonflies did not get a viable habitat for their lives.

Considering 7 species that vulnerable to environmental pollution and the presence of 3 endemic species of Javan island exist around the waterfall, governments of Yogyakarta and Central Java as the stage holder and also tourism management should concern principles of conservation in waterfall tourism and also in other tourism, so the extinction of dragonfly species does not happen.

\section{ACKNOWLEDGMENT}

We would like to say thanks for our family in Biology Education Department, Yogyakarta State University and the Faculty of Biology, Gajah Mada University which is dedicated to this research. Thanks to Our Parents thats always support us and also our Dragonfly Community: Joko Setiyono, Alif Prambudi, Prajawan Kusuma Wardhana, Ahmad Zulfikar
Abdullah, Tria Subagyo, Sari Trisnaningsih, Asman Adi Purwanto who has help in the identification, data collection and documentation. Menoreh Karst management who have given permission for our research as well as those who was helped in the this paper finishing.

\section{REFERENCES}

[1] E.P. Odum. Dasar - dasar ekologi, Yogyakarta.: UGM press, 1999, ch.3, pp. 178-180.

[2] G. Theischinger. Identification Guide To The Australian Odonata. Australia, Australia.: Department of Environment, Climate Change and Water NSW, 2009, 1-55.

[3] Lupiyaningdyah. Pungki. Capung (Odonata) Di Kawasan Menoreh Karst Dan Gunungsewu, Jawa Tengah Dan Yogyakarta, Bogor.: LIPI, 2015.

[4] Paulson, D. 2006. The Importance Of Forest To Neotro-Pical Dragonflies. - In Cordero Rivera, A. (Ed.), Forest And Dragonflies. Pensoft Publishers, sofia.

[5] P.S. Corbet. 1999. Dragonlies Behaviour and Ecology of Odonata, Essex, England.: Harley Books, 1999.

[6] Rohman, Abdu. "Distribusi Capung (Odonata) Di Kawasan Karst Gunung Sewu Pracimantoro Wonogiri”. S.Si. Undergraduated Thesis, Dept . Biology. Yogyakarta State University., Yogyakarta, Indonesia, 2010.

[7] Rohman, Abdu. "Identifikasi Capung (Odonata) Kawasan Menoreh Karst ”. M.Sc. Thesis, Dept . Biology. Gadjah Mada University., Yogyakarta, Indonesia, 2015.

[8] Sahlén, G. \& K. Ekestubbe 2001. Identification Of Dragonflies (Odonata) As Indicators Of General Species Richness In Boreal Forest Lakes. - Biodiversity and conservation 10: 673-690. http://dx.doi.org/10.1023/A:1016681524097

[9] Sidiq Harjanto. (April 2011). Potensi Kawasan Menoreh Karst . Pemda Diy. Katalog DIY. [Online]. Available: http://www.plazainformasi.jogjaprov.go.id

[10] T.E Clark, and M.J Samways. (Oct 1996). Dragonflies (Odonata) as indicators of biotope quality in the Kruger National Park, South Africa. Journal of Applied Ecology [J. Appl. Ecol.], vol. 33, no. 5, pp. 1001$1012 . \quad$ Available

https://www.researchgate.net/publication/239519321_Dragonflies_Odo nata_as_indicators_of_biotype_quality_in_the_Kruger_National_Park. http://dx.doi.org/10.2307/2404681 